\title{
PREVALENCE OF ANAEMIA AMONG ADOLESCENT SCHOOL GOING CHILDREN IN GUNTUR
}

\author{
Phanindra Dulipala1, Chaitanya Gujjarlapudi²
}

${ }^{1}$ Assistant Professor, Department of Community Medicine, Katuri Medical College, Guntur. ${ }^{2}$ Associate Professor, Department of Community Medicine, Katuri Medical College, Guntur.

\section{ABSTRACT}

\section{BACKGROUND}

Anaemia is a nutritional problem worldwide and its prevalence is higher in developing countries when compared to the developed countries. Anaemia, a manifestation of under-nutrition and poor dietary intake of iron is a public health problem, not only among pregnant women, infants and young children, but also among adolescents. Recent studies on the prevalence of anaemia have been conducted on preschool children only, so there is a need for more studies related to anaemia among school children. The present study was done to estimate the prevalence of anaemia among school children aged 10-15 years from Guntur, Andhra Pradesh.

\section{MATERIALS AND METHODS}

A cross-sectional study was conducted among 500 school children aged 10 to 15 years. Purposive sampling was used to include 250 boys and 250 girls. Haemoglobin estimation was done by cyanmethaemoglobin method. The severity of anaemia was classified on the basis of WHO criteria into Mild, Moderate and Severe. Data analysis was done by SPSS version 21.

\section{RESULTS}

The overall prevalence of anaemia was $27.4 \%$ in the present study. A higher prevalence of anaemia was observed among girls (42.4\%) than boys (12.4\%). The prevalence of mild anaemia was $34.4 \%$ and $9.6 \%$ among girls and boys respectively.

\section{CONCLUSION}

The prevalence of anaemia is high among school going adolescents. Special emphasis should be given on nutritional supplementation with iron and health education for this age group.

\section{KEYWORDS}

Adolescent, Anaemia, School Children.

HOW TO CITE THIS ARTICLE: Dulipala P, Gujjarlapudi C. Prevalence of anaemia among adolescent school going children in Guntur. J. Evolution Med. Dent. Sci. 2016;5(49):3132-3135, DOI: 10.14260/jemds/2016/727

\section{INTRODUCTION}

Anaemia is a condition in which the number of red blood cells or their oxygen-carrying capacity is insufficient to meet physiologic needs which vary by age, sex, altitude, smoking and pregnancy status.[1] In clinical terms, anaemia is defined as an insufficient mass of RBCs circulating in the blood. In public health terms, anaemia is defined as a haemoglobin concentration below the threshold levels given by WHO.[2] Nutritional anaemia refers to a condition, in which the haemoglobin content of the blood is lower than normal due to a deficiency of one or more essential nutrients regardless of the cause of such deficiency.[3]

Globally, the most significant contributor to the onset of anaemia is iron deficiency, so that Iron Deficiency Anaemia (IDA) and anaemia are often used synonymously and the prevalence of anaemia has often been used as a proxy for IDA. It is generally assumed that $50 \%$ of the cases of anaemia are due to iron deficiency, but the proportion may vary among population groups and in different areas according to the local conditions. ${ }^{[4]}$

Financial or Other, Competing Interest: None.

Submission 05-03-2016, Peer Review 28-05-2016,

Acceptance 03-06-2016, Published 17-06-2016.

Corresponding Author:

Dr. Phanindra Dulipala,

Assistant Professor,

Department of Community Medicine,

Katuri Medical College,

Guntur- 522019.

E-mail:drpdulipala@gmail.com

DOI: $10.14260 /$ jemds/2016/727
The main risk factors for IDA include a low intake of iron, poor absorption of iron from diets and periods of increased demand for iron, i.e. puberty and pregnancy. Among the other causes of anaemia, heavy blood loss during menstruation or parasitic infections such as hookworms, ascaris and schistosomiasis can lower blood haemoglobin (Hb) concentrations.[2]

Anaemia is an indicator of both poor nutrition and poor health. The most dramatic health effects of anaemia, i.e. increased risk of maternal and child mortality due to severe anaemia have been well documented..5-7] In addition, the negative consequences of IDA on cognitive and physical development of children and on physical performanceparticularly work productivity in adults-are of major concern.[6] Since the technological advancement and economic development of a nation depend heavily on its trained human resources, the behavioural effects of anaemia are highly relevant. Consequently, if anaemia is highly prevalent in a country, it can substantially affect its intellectual and economical potential.

Anaemia is a global public health problem affecting both developing and developed countries with three to four times higher prevalence in developing countries.[8] Pregnant women, infants, young children and adolescents are more vulnerable for this problem.

The World Health Organization has defined adolescence as the age period between 10 to 19 years of age for both the sexes (Married and unmarried).[9] The word adolescence is derived from the Latin word, "adolescere," which means "to grow, to mature."[10] 
This is the formative period of life when the maximum amount of physical, psychological and behavioural changes take place. This is a vulnerable period in the human life cycle for the development of nutritional anaemia, which has been constantly neglected by public health programs. Adolescents are at high risk of iron deficiency and anaemia due to accelerated increase in requirements for iron, poor dietary intake of iron, high rate of infection and worm infestation as well as the social norm of early marriage and adolescent pregnancy. During this stage the requirement of nutrition and micronutrients is relatively high. Therefore, adolescents, especially girls are vulnerable to iron deficiency mainly because requirements are at a peak.[11]

The magnitude of the anaemia has been well-documented in pregnant women and infants; however, there is scarce data on the prevalence of anaemia in school children.(12) The present study was undertaken to estimate the prevalence of anaemia among school children aged 10-15 years from Guntur, Andhra Pradesh.

\section{MATERIALS AND METHODS}

The present cross-sectional study was conducted during the months of October and November 2015 in a missionary school, Guntur city, after obtaining approval from the Institutional Ethics Committee. The investigator contacted the principal of school personally. The objective and nature of the study was explained and a verbal consent was sought to carry out the survey in the school.

The study included only school going adolescent children aged 10-15 years. A total of 500 children ( 250 boys and 250 girls) included in the study were selected by purposive sampling. The study was explained to the school authorities, confidentiality was assured and informed oral consent was obtained.

The informed written consent was obtained from each student and in case of any student who was not willing to participate in study the next student was involved. Every selected student was called one by one in the separate room with the help of school personnel without any interference in studies and other routine activity. While collecting the sample from the female students, the help from female teacher was sought and she was asked to stay in the class room.

The purpose of the survey was explained and assurance about the confidentiality of the information was given to the students. Interview was started with general discussion to build up a rapport with respondents and to gain their confidence.

Haemoglobin estimation was done by cyanmethaemoglobin method.[13] The haemoglobin estimation was obtained by finger prick method using sterile needles; $20 \mu \mathrm{L}$ of blood sample was collected in $5 \mathrm{~mL}$ Drabkin solution. Haemoglobin in the blood is converted into cyanmethaemoglobin. The absorbance of cyanmethaemoglobin was measured at $540 \mathrm{~nm}$ by photoelectric colorimeter on the same day of sample collection. The severity of anaemia was classified on the basis of WHO criteria, i.e. Severe anaemia ( $\mathrm{Hb} \%<7 \mathrm{~g} / \mathrm{dL}$ ), Moderate anaemia ( $\mathrm{Hb} \%$ - 7-9.9 g/dL) and Mild anaemia (Hb\% of 10-12.9 g/dL in boys and 10-11.9 g/dL in girls).(1) The complete data was compiled into MS EXCEL 2007 and analysis was done by SPSS version 21 .

\section{RESULTS}

The present cross-sectional study was conducted in a missionary school in Guntur among children aged 10-15 years. Age wise distribution was shown in Table 1. The overall prevalence of anaemia was $27.4 \%$ in the present study and $72.6 \%$ of the 500 participants were non-anaemic. Children who participated in the study did not show any symptoms like easy fatigue or dizziness. A total of 137 children out of 500 were having varying severity of anaemia. A higher prevalence of anaemia was observed among girls $(42.4 \%)$ than boys $(12.4 \%)$ (Table 2). The difference was highly significant statistically (p value $>0.05$ ).

Out of 250 girls, $42.4 \%$ girls have varying degree of severity of anaemia, which includes $34.4 \%$ mildly anaemic, $6.8 \%$ moderately anaemic and $1.2 \%$ were severely anaemic. On the other hand out of 250 boys, $12.4 \%$ have varying degree of severity of anaemia, which includes $9.6 \%$ mildly anaemic, $2.4 \%$ moderately anaemic and $0.4 \%$ were severely anaemic. Thus the prevalence of mild, moderate and severe anaemia was observed to be higher among girls than boys. (Table 3).

\begin{tabular}{|c|c|c|}
\hline Age in Years & Boys (\%) & Girls (\%) \\
\hline $10-11$ & $72(28.8)$ & $82(32.8)$ \\
\hline $12-13$ & $87(34.8)$ & $83(33.2)$ \\
\hline $14-15$ & $91(36.4)$ & $85(34.0)$ \\
\hline Total & 250(100) & $\mathbf{2 5 0 ( 1 0 0 )}$ \\
\hline \multicolumn{2}{|c|}{ Table 1: Age Wise Distribution } \\
\hline
\end{tabular}

\begin{tabular}{|c|c|c|}
\hline Gender & Boys (\%) & Girls (\%) \\
\hline Anaemia & $31(12.4)$ & $106(42.4)$ \\
\hline No Anaemia & $219(87.6)$ & $144(57.6)$ \\
\hline Total & $\mathbf{2 5 0}(\mathbf{1 0 0})$ & $\mathbf{2 5 0}(\mathbf{1 0 0})$ \\
\hline \multicolumn{2}{|c|}{ Table 2: Gender wise Prevalence of Anaemia } \\
\hline
\end{tabular}

$\chi^{2}=56.55 ; p$ value $<0.001$; highly significant

\begin{tabular}{|c|c|c|}
\hline Grade of Anaemia & Boys (\%) & Girls (\%) \\
\hline Severe Anaemia & $1(0.4)$ & $3(1.2)$ \\
\hline Moderate Anaemia & $6(2.4)$ & $17(6.8)$ \\
\hline Mild Anaemia & $24(9.6)$ & $86(34.4)$ \\
\hline No Anaemia & $219(87.6)$ & $144(57.6)$ \\
\hline Total & $250(100)$ & $250(100)$ \\
\hline
\end{tabular}

\section{DISCUSSION}

The overall prevalence of anaemia was found to be $27.4 \%$ in the present study. This is in similar to the finding observed in a study conducted in rural south India by Joseph AG and others. ${ }^{[14]}$ In a multi-country study on the nutritional status of adolescents, which was carried out by the International Centre for Research on Women (ICRW), anaemia was found to be the most widespread nutritional problem and its prevalence ranged from $32-55 \% .[15]$

Higher prevalence of anaemia was observed in girls in comparison to boys. This variation was highly significant. Similar findings have been reported in studies conducted by Basu et al(15) and Jai Prabhakar et al(16) in other parts of India. The prevalence of anaemia among girls was $42.4 \%$. Similar finding was reported from a study conducted in rural Tamil 
Nadu by Rajaratnam et al where the overall prevalence of anaemia was $44.8 \%{ }^{[17]}$ A variable prevalence $(23.9 \%$ $81.8 \%$ ) of anaemia in adolescent girls has been reported in different studies conducted in India.[18]

National Family Health Survey (NFHS), 3 estimates reveal the prevalence of anaemia to be $65-75 \%$ in adolescent girls.[19]

The following cut off points, which were suggested by the WHO were used to determine whether iron deficiency anaemia was a major problem among the general population.[20]

\begin{tabular}{|c|c|}
\hline Prevalence & Public Health Problem \\
\hline$<5 \%$ & Not a problem \\
\hline $5-14.9 \%$ & Low magnitude \\
\hline $15-39.9 \%$ & Moderate magnitude \\
\hline $40 \%$ and above & High magnitude \\
\hline
\end{tabular}

The problem of anaemia is of very high magnitude in a community when prevalence rate exceeds $40 \%$. This is a serious public health problem. Thus, the prevalence of $42.4 \%$ among adolescent school going girls as observed in our study is a serious public health problem and the prevalence of $12.4 \%$ of anaemia among boys considered as a problem of low magnitude.

On the basis of severity, mild anaemia was observed among most of the participants. Similar observation was reported by Shanti et al, in a school based study done in Haryana.(20) The prevalence of mild, moderate and severe anaemia was observed to be higher among girls than boys. Similar findings were observed in the studies conducted by Sudhagandhi et al(16) and Muthayya et al.(21)

The overall prevalence of severe, moderate and mild anaemia in the present study was $0.8 \%, 4.6 \%$ and $22 \%$ respectively. This was lower than the findings reported by Verma et al from their study conducted among college going youths in rural northern India where the prevalence of severe, moderate and mild anaemia were $3.58 \%, 11.16 \%$ and $29 \%$ respectively. ${ }^{[22]}$ The prevalence of severe, moderate and mild anaemia among girls in the present study was $1.2 \%$, $6.8 \%$ and $34.4 \%$ respectively. These findings were almost consistent to those reported from a study conducted in rural Tamil Nadu where severe anaemia was $2 \%$, moderate anaemia was $6.3 \%$ and mild anaemia was $36.5 \%{ }^{[17]}$

\section{LIMITATION}

This study was conducted in only one missionary school and if it is done in other settings like government schools, results may vary. So the results cannot be generalized.

\section{STRENGTHS}

Haemoglobin estimation was done by cyanmethaemoglobin method.

\section{CONCLUSION}

The present study revealed that anaemia continues to be a major health problem among the adolescents. There was a higher prevalence of mild anaemia as compared to moderate and severe anaemia. There is a significant difference observed among adolescent boys and girls with respect to the prevalence of anaemia. This age group should be screened regularly and appropriate measures taken for correction of anaemia.

\section{REFERENCES}

1. World Health Organization. Control of nutritional anaemia with special references to iron deficiency anaemia: Report of an IAEA/USAID/WHO joint meeting. Geneva: WHO; NO. 580, 1975.

2. UNICEF/United Nations University/World Health Organization. Iron deficiency anaemia. Assessment, prevention, and control: a guide for programme managers. Document WHO/NHD/01.3. Geneva: World Health Organization; 2001.

3. National consultation of control of nutritional anaemia in India. Department of Family Welfare (Maternal Health Division). Ministry of health and family welfare. New Delhi: Nirman Bhawan; 1998.

4. World Health Organization: Reducing risks, promoting healthy life; The World Health Report 2002.

5. Macgregor MW. Maternal anaemia as a factor in prematurity and perinatal mortality. Scottish Medical Journal 1963;8:134-40.

6. Scholl TO, Hediger ML. Anaemia and iron-deficiency anaemia: compilation of data on pregnancy outcome. American Journal of Clinical Nutrition 1994;59(2 Suppl):492S-500S.

7. Bothwell $\mathrm{T}$, Charlton R, eds. Iron deficiency in women. Washington DC, Nutrition Foundation, 1981.

8. WHO/CDC, Worldwide Prevalence of Anaemia 19932005 WHO Global Database on Anaemia, WHO Press, Geneva, Switzerland, 2008.

9. Adolescent health and development. WHO Regional office for South-East Asia. Last accessed on 2016 Feb. 3. Available from:

http://www.searo.who.int/entity/child_adolescent/top ics/adolescent_health/en/index.html .

10. WHO. Young People's Health. A Challenge for Society. WHO Technical Report Series no 731, WHO, Geneva, Switzerland 1986.

11. Stang J, Story M. Chapter 1. Adolescent growth and development. Guidelines for adolescent nutrition services. Minneapolis, MN Center for Leadership, Education and training in maternal and child nutrition, Division of epidemiology and community health, school of public health, university of Minnesota. 2005. Last accessed on Feb 20, 2016.

Available from:

http://www.epi.umn.edu/let/pubs/img/adol_ch1.pdf .

12. Sudhagandhi B, Sundaresan S, William WE, et al. Prevalence of anaemia in the school children of Kattankulathur, Tamil Nadu, India. Int J Nutr Pharmacol Neurol Dis 2011;1(2):184-8.

13. Kapoor SK, Kapil U, Dwivedi SN, et al. Comparison of hemocue method with cyanmethemoglobin method for estimation of hemoglobin. Indian Paediatr 2002;39: 743-6.

14. Joseph AG, Bhattacharji S, Joseph A, et al. General and reproductive health of adolescent girls in rural south India. Indian Paediatr 1997;34:242-4.

15. Basu S, Basu S, Hazarika R, et al. Prevalence of anaemia among school going adolescents of Chandigarh. Indian Paediatr 2005;42(6):593-7.

16. Jai Prabhakar SC, Gangadhar MR. Prevalence of anaemia in jenukuruba primitive tribal children of Mysore District, Karnataka. Anthropologist 2009;11(1):49-51. 
17. Rajaratnam J, Abel R, Asokan JS, et al. Prevalence of anaemia among the adolescent girls of rural Tamil Nadu. Indian Paediatr 2000;37:532-6.

18. Kulkarni MV, Durge PM, Kasturwar NB. Prevalence of anaemia among adolescent girls in an urban slum. National J Comm Med 2012;3(1):108-11.

19. International Institute for Population Sciences (IIPS) and ORC Macro. National Family Health Survey (NFHS) III, 2005-06. Mumbai: IIPS, 2007.
20. Shanti D, Vidya D, Ramesh V. Prevalence of anaemia among adolescent girls: a school based study. Intl J Basic Appl Med Sci 2015;5:95-8.

21. Muthayya S, Thankanchan P, Zimmermann MB, et al. Low anaemia prevalence in school aged children in Bangalore, South India: possible effect of school health initiative. Eur J Clin Nutr 2007;61(7):865-9.

22. Verma R, Govila VK, Kuldeep, et al. Prevalence of anaemia in college going youths in rural blocks of a dist. of northern India. EXCEL Intern J Multidiscipl Management Stud 2013;3(2):15-22. 